\title{
A follow-up study of people with severe mental illness treated by a specialist homeless team
}

\author{
Sue Odell and Martin Commander
}

\begin{abstract}
Aim and method To follow up homeless people with psychoses treated by a dedicated team; changes in accommodation, risk behaviour, mental state and psychiatric care were examined.

Results Service uptake improved as did symptomatology and residential stability. However, substance use and criminality continued to be prevalent and a minority remained homeless.

Clinical implications Specialist psychiatric teams are a valuable adjunct to mainstream services in areas with high levels of homelessness.
\end{abstract}

Inner-city psychiatric services, struggling to meet expectations regarding community care for the severely mentally ill (SMI: House of Commons, 1994), have been unable, and sometimes unwilling, to take on the problems of the growing numbers of homeless people who gravitate to the run-down areas of our larger cities. Consequently, despite reservations about marginalising an already alienated section of the population, dedicated psychiatric teams providing care to homeless people with SMI have been established both in London (Craig et al. 1995) and elsewhere (Commander et al, 1997a). Although proven to be successful in targeting a highly vulnerable population with extensive clinical and social needs (Commander et al, 1997a) as yet little evidence exists about the outcomes for people involved with these services (Craig et al. 1995).

In 1994 a specialist community mental health team for homeless people (CMHTH) was commissioned in Birmingham. For most of the duration of this study, the team consisted of a half-time consultant psychiatrist (MC), three community psychiatric nurses, one social worker and two resettlement officers. It was supported by a full-time secretary and operated between 9 a.m. -5 p.m. Monday to Friday. Emergencies outside of office hours were dealt with by existing duty services and admission to hospital was arranged according to a No Fixed
Abode' rota of consultants operating across the city (Commander et al, 1997b). People taken on for an episode of care were allocated a key worker and co-worker who were the main care providers, albeit working closely with a wide range of agencies. Interventions were patientled and often focused on housing and benefit issues during the early stages. Nevertheless, it was clear that team members were mental health professionals and, for example, medication frequently formed a component of care plans.

The aim of this follow-up study was to examine the outcomes for people with a clinical diagnosis of a psychotic disorder (including those with a comorbid substance use disorder) treated by the CMHTH during its first two years of operation (August 1994 July 1996).

\section{The study}

Team members collected information as part of their initial assessment, using routine documentation and research proforma. Ratings included details on accommodation, forensic history, work and daily activities, benefits, family contacts, past psychiatric treatment and current mental state. Symptoms were rated on a scale from 0 (no problem) to 3 (severe) according to their impact on the person's ability to deal with everyday life (derived from the FACE Profle: Clifford, 1993). Details on service provision and changes in accommodation during care episodes were recorded and assessment ratings subsequently repeated. For people who had multiple care episodes only the initial assessment and a final outcome rating were used in the analyses. The latter was taken either as the end date of the last care episode or, if the person was still open to the CMHTH, as 1 January 1997. Data were analysed using SPSS version 6.0 (SPSS, 1993). Differences in ratings were tested using McNemar and Wilcoxon matched pairs tests. 


\section{Findings}

\section{Sample}

During the first two years 522 people were referred to the team (see Commander et al, $1997 a$ for details). Of these, a small proportion $(n=31,6 \%)$ did not require psychiatric care (and were offered advice about alternative services) or either refused contact or left before an assessment could be undertaken $(n=68,13 \%)$. Others were transferred to or found to be already in contact with a mental health team ( $n=84,16 \%)$ while a few with primary substance use problems were directed to specialist addiction services $(n=21,4 \%)$.

The team assessed 318 people $(61 \%)$ of whom $118 \mathrm{had}$ a psychotic disorder. A few of the latter had experienced brief psychotic episodes and were offered advice only $(n=5,4 \%)$, a small number $(n=9,8 \%)$ refused to be seen or left before an assessment could be completed while 22 (19\%) were referred on to other psychiatric services.

Of the remaining 82 people (69\%) with psychoses taken on for an episode of care by the CMHTH, 29 (35\%) were still open to the team at the end of the follow-up period, 21 (26\%) had been discharged to other psychiatric services and $10(12 \%)$ to a general practitioner while 17 $(21 \%)$ had left the area and two $(2 \%)$ refused to have any involvement with services. Three people (4\%) died; one had an accidental fall, another had respiratory failure and for the third the cause of death was unexplained.

The majority of the sample were male $(n=71$, $87 \%)$, white $(n=69,84 \%)$ and single $(n=77,84 \%)$. Their mean age was 38 years (s.d. $=11$; range 20$70)$. Less than half were born in Birmingham and

Table 1. Residential mobility, risk behaviour and psychiatric care details

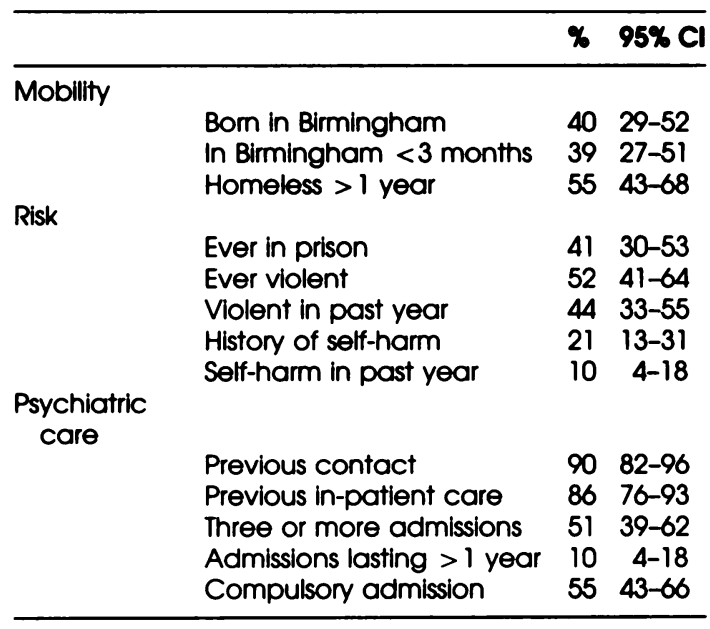

a similar proportion had been in the city for less than three months (Table 1). Around half had histories of homelessness (defined as the time since last in a private household for six months or more) dating back more than a year. Levels of harm to self and to others were high as were rates of past contact with psychiatric services (including compulsory admissions).

\section{Psychiatric care and symptomatology}

The median length of the care episode (from initial assessment until final rating) was 323 days (range 33-912). During their care episode, 14 people $(17 \%)$ had a period of at least three months out of contact with the CMHTH. Nineteen (23\%) refused to see team members at some point although this dropped to 11 people (14\%) in the final three months. Seventeen people (21\%) refused medication completely. Half the people ( $n=42,51 \%)$ had at least one hospital admission, many were admitted compulsorily $(n=31,38 \%)$ and one-quarter remained in-patients for over three months ( $n=20,24 \%)$. Of the 57 people $(70 \%)$ who were either discharged or who refused/left the service at some time during their care episode 15 were accepted back for further treatment.

Six people had one or more incidents of deliberate self-harm during their care episode. There were significant reductions in the proportion of people with delusions and hallucinations rated as having a moderate or severe impact on the person's life by the final outcome rating (Table 2). Although consistently lower, there were no significant changes for substance use or depressed mood.

\section{Accommodation}

At the initial assessment most patients were living in direct access hostels ('establishments offering basic accommodation to anyone at any time, irrespective of a need for appointments or referral via an agency'; Wadhams et al, 1997) or were roofless but by the final rating just over a third were in private accommodation while one in five were living in other hostel provision (Table 2). A substantial minority (13\%) occupied either care/nursing home places or long-stay psychiatric beds.

Residential mobility was high, 39 people (48\%) moving three or more times and 5 people more than 10 times during their care episodes. However, this situation improved and at followup just over half the people had been living at their address for three months or more (Table 2). Nineteen people (23\%) slept rough at some time, two (both still open to the team) for the total duration of their care episode. Nevertheless, there was a significant reduction in rough 
Table 2. Comparison of symptomatology and accommodation details at assessment and follow-up

\begin{tabular}{|c|c|c|c|c|c|}
\hline & $\begin{array}{l}\text { Assessment } \\
n\end{array}$ & $\%$ & $\begin{array}{l}\text { Final rating } \\
n\end{array}$ & $\%$ & $\boldsymbol{P}$ \\
\hline \multicolumn{6}{|l|}{ Symptoms' ${ }^{1}$} \\
\hline Hallucinations & 29 & 35 & 15 & 18 & 0.003 \\
\hline Delusions & 41 & 50 & 22 & 27 & 0.0002 \\
\hline Depressed mood & 10 & 12 & 7 & 9 & NS \\
\hline Alcohol use & 20 & 24 & 19 & 23 & NS \\
\hline Drug use & 18 & 22 & 13 & 16 & NS \\
\hline \multicolumn{6}{|l|}{ Accommodation } \\
\hline Type of accommodation & & & & & 0.001 \\
\hline Rough sleeping/no fixed abode (NFA) & 14 & 17 & 3 & 4 & \\
\hline Direct access hostel & 56 & 68 & 15 & 18 & \\
\hline Other hostel & 10 & 12 & 22 & 27 & \\
\hline Care/nursing home & - & - & 5 & 6 & \\
\hline Hospital & - & - & 6 & 7 & \\
\hline House/flat/bedsit & 2 & 2 & 31 & 38 & \\
\hline Time at accommodation ${ }^{2}$ & & & & & $<0.0001$ \\
\hline Less than three months & 79 & 96 & 39 & 48 & \\
\hline Three or more months & 3 & 4 & 43 & 52 & \\
\hline Number of moves in past three months ${ }^{3}$ & & & & & 0.0009 \\
\hline Less than three & 55 & 67 & 72 & 88 & \\
\hline Three or more & 27 & 33 & 10 & 12 & \\
\hline
\end{tabular}

1. Rated as moderate/severe.

2. Rough sleeping/NFA included in <three months.

3. Rough sleeping/NFA included in >three months.

sleeping when the three months prior to assessment were compared with the final ratings (29 $(35 \%)$ to $6(7 \%) ; P<0.0001)$. Eighteen people (22\%) never exited a circuit of rough sleeping/ direct access hostels/prison/hospital.

\section{Activities, finances and family contact}

At initial assessment no people were employed or had regular daytime activities but by the final rating 13 had some structured daily activities, two of whom were working full-time. There was a significant increase in the number of patients in receipt of Disability Living Allowance (18 (22\%) to 50 (61\%); $P<0.0001$ ), and 37 patients (45\%) received a community care grant during their care episode. There was little change in the number of patients in contact with family (38 $(46 \%)$ to $44(54 \%))$ and the CMHTH made contact with a family member in only 32 cases (39\%).

\section{Forensic}

Three patients went to prison during their care episode; the charges were of theft and criminal damage and none were detained for more than three months. Twenty (24\%) were involved in violent incidents towards others. However, there was a significant reduction in police involvement during the three months prior to the final rating compared to at initial assessment (35 (43\%) to 19 (23\%); $P=0.006$ ).

\section{Primary care}

Permanent registration with a general practitioner (GP) increased significantly $(8(10 \%)$ to 51 (62\%); $P<0.0001)$ yet one in five people $(n=16)$ remained without even temporary registration.

\section{Comment}

The lack of a control group in this study makes it difficult to confidently link improvements to team interventions. Furthermore, no fixed time period elapsed before the final rating, the duration of care episodes varying widely. As most people were in dire circumstances at assessment one could have expected a tendency to improve regardless. It is also acknowledged that the data were limited in scope and were collected by staff who had a vested interest in demonstrating the benefits of the service.

During their care episodes, people were highly mobile, and many slept rough, emphasising the necessity of peripatetic services if continuity of care is to be assured. However, contrary to popular characterisations of the homeless mentally ill as service refusers, registration with GPs was substantially increased, the level of contact with psychiatric services was high and the majority of people were compliant with medication. Also, extensive use was made of in-patient care reinforcing the need for close links between hospital and community services (Commander et 
$a l, 1997 b$ ). A reduction in psychotic symptoms did occur but less impact was made on drug and alcohol use. The value of training staff in the therapeutic techniques aimed specifically at people with dual diagnoses deserves consideration (Drake et al, 1997).

Many people obtained additional benefits. In some cases this increased income undermined other team efforts by contributing both to greater substance misuse and a reluctance to move into supportive accommodation (where some of their money would go in payment). The initial absence of structure to each person's week was not unexpected but the team's inability to subsequently find and engage people in suitable leisure and employment activities (many rejecting traditional psychiatric day units) was disappointing, especially considering their low levels of contact with family and poor social networks (Harris \& Bergman, 1985). The entrenched patterns of violence and criminality exhibited by some people also posed problems for which solutions remained unclear.

The team was successful in gaining independent accommodation for many people as well as helping them to retain it. Yet others remained in hostel accommodation despite an expressed wish to get their own place. Also, a number of people continued to move frequently or persistently slept rough. More thought should be given to the factors which hinder people moving to and retaining accommodation such as poor budgeting, loneliness and boredom. A shift away from hostel provision towards flexible on-going support available to patients in their own homes is arguably required (Carling, 1993). However, the fact that a significant minority of people required accommodation with 24-hour support also indicates the necessity for more intensive provision. The absence of supportive accommodation acceptable to people (e.g. for financial reasons or due to the nature of the regime) and accepting of them (e.g. because of behavioural problems or substance use) was a recurrent issue. In the absence of a comprehensive range of residential alternatives (Prior, 1996) the best efforts of dedicated homeless outreach and resettlement teams will be undermined.

\section{References}

CARLING, P. (1993) Housing and supports for persons with mental illness: Emerging approaches to research and practice. Hospital and Community Psychiatry. 44, 439449.

CLIFFORD, P. (1993) FACE Profile. London: Royal College of Psychiatrists.

COMmander, M. J., Odell, S. \& SASHidhaRAN, S. P. (1997a) Birmingham community mental health team for the homeless: one year of referrals. Psychiatric Bulletin, 21. 74-76.

- $-\&-(1997 b)$ Psychiatric admission for homeless people: the impact of a specialist community mental health team. Psychiatric Bulletin, 21, 260-263.

CraIg, T., BAYLISS, E., KLEIN, O., et al (1995) The Homeless Mentally III Initiative: An Evaluation of Four Clinical Teams. London: Department of Health/Mental Health Foundation.

DRAKE, R. E., Yovetich, N. A., BEBOUT, R. R., et al (1997) Integrated treatment for dually diagnosed homeless adults. Journal of Nervous and Mental Disorders, 186. 298-305.

HARRIS, M. \& BERGMAN, H. C. (1985) Networking with young adult chronic patients. Psychosocial Rehabilitation Journal, 8, 28-35.

House of COMmONS HEALTH COMMTTEE (1994) Better off in the Community. The Care of People who are Seriously Mentally IIL. London: HMSO.

PRIOR, C. (1996) Housing component of mental health services. In Commissioning Mental Health Services (eds G. Thornicroft \& G. Strathdee). London: Department of Health.

SPSS (1993) SPSS for Windows. Release 6.0. Chicago: SPSS Inc.

WADHAMS, C., GROVES, R. \& LANGSTAFF, B. (1997) Managing at the Margins. The Role of Voluntary Sector Direct Access Hostels in Birmingham. Birmingham: University of Birmingham.

Sue Odell, Research Associate and Martin Commander, Senior Research Fellow, University of Birmingham, Academic Unit, 71 Fentham Road, Birmingham B23 6AL

*Correspondence 